\title{
Non-destructive characterization of superionic conductor: lithium nitride
}

\author{
PRAMOD KUMAR YADAWA*
}

Department of Applied Physics, AMITY School of Engineering and Technology, Bijwasan, New Delhi-110 061, India

\begin{abstract}
Higher order elastic constants have been calculated in hexagonally structured superionic conductor $\mathrm{Li}_{3} \mathrm{~N}$ at room temperature using the interaction potential model. The temperature variation of the ultrasonic velocities was evaluated along different angles with $\mathrm{z}$ axis (unique axis) of the crystal, using the second order elastic constants. The ultrasonic velocity decreased with the temperature along a particular orientation of the unique axis. Temperature variation of the thermal relaxation time and Debye average velocities was also calculated along the same orientation. The temperature dependency of ultrasonic properties was discussed in correlation with elastic, thermal and electrical properties. It has been found that the thermal conductivity is the main contributor to the behavior of ultrasonic attenuation as a function of temperature and the cause responsible for attenuation is phonon-phonon interaction. The mechanical properties of $\mathrm{Li}_{3} \mathrm{~N}$ at low temperature are better than at high temperature because at low temperature it has low ultrasonic attenuation. Superionic conductor lithium nitride has many industrial applications, such as those used in portable electronic devices.
\end{abstract}

Keywords: elastic properties; thermal conductivity; ultrasonic properties; superionic conductor lithium nitride

(C) Wroclaw University of Technology.

\section{Introduction}

Development of solid-state materials with superionic conductivities is critical to solid-state battery technologies [1]. In addition to the application of solid ionic conductors in batteries, there is a wide range of potential technological applications in solid-state devices, such as solid oxide fuel cells, water hydrolysis cells and chemical sensors [2]. In the past four decades, a remarkably large number of lithium-containing solid ionic conductors, such as lithium $\beta$-alumina, lithium silicates, lithium aluminosilicate and lithium nitrides have been extensively investigated [3-6]. Among these lithium solid ionic conductors, lithium nitride $\left(\mathrm{Li}_{3} \mathrm{~N}\right)$ is of special interest and has attracted particular attention because of its high ionic conductivity [7-10] and its capacity for hydrogen storage [11].

Lithium nitride is a superionic conductor with several interesting properties at room temperature

*E-mail: pkyadawa@rediffmail.com and potentials for use [12-16]. Most members of this class of materials are non-stoichiometric compounds and are characterized by their crystal structure containing more cation lattice sites than cations. This feature is responsible for the observed high ionic mobility [17]. Superionic conductor lithium nitride has many industrial applications, which are used in portable electronic devices [18-20].

Increased competition and needs of higher productivity and better products from materials producing industries are creating more stringent requirements for process and quality control and call for advances in non-destructive techniques, which could be used to characterize the materials not only after production but during the process, as well. Ultrasonic investigations provide an important diagnostic tool for microstructural properties as well as deformation processes in a material, controlling material behavior based on the physical mechanism to predict future performance of the materials. Various investigators have shown considerable interest in 
ultrasonic properties of metals, intermetallics and compounds [21-24]. Wave propagation velocity is a key parameter in ultrasonic characterization and can provide information about crystallographic texture $[25,26]$.

Ultrasonic attenuation is a very important physical parameter to characterize the material, which is well related to several physical quantities like thermal conductivity, specific heat, thermal energy density and higher order elastic constants [27]. The elastic constants provide valuable information about the bonding characteristics between adjacent atomic planes and the anisotropic character of the bonding and structural stability [28, 29].

Therefore, in this work we have studied the ultrasonic properties of hexagonal structured $\mathrm{Li}_{3} \mathrm{~N}$ compound at different temperatures. The ultrasonic attenuation coefficient, acoustic coupling constants, higher order elastic constants, thermal relaxation time and ultrasonic wave velocities for $\mathrm{Li}_{3} \mathrm{~N}$ for a unique direction of propagation of wave were calculated as a function of temperature. The calculated ultrasonic parameters were discussed with related thermophysical properties for the characterization of the chosen compound. The obtained results were analyzed in comparison to other hexagonal structured materials.

\section{Theory}

In the present investigation, the theory is divided into two parts.

\subsection{Second and third order elastic con- stants}

The second $\left(\mathrm{C}_{I J}\right)$ and third $\left(\mathrm{C}_{I J K}\right)$ order elastic constants of material are defined by following expressions:

$$
\begin{gathered}
C_{I J}=\frac{\partial^{2} U}{\partial e_{I} \partial e_{J}} ; \quad \text { I or } \mathrm{J}=1, \ldots 6 \\
C_{I J K}=\frac{\partial^{3} U}{\partial e_{I} \partial e_{J} \partial e_{K}} ; \text { I or } \mathrm{J} \text { or } \mathrm{K}=1, \ldots 6
\end{gathered}
$$

where, $\mathrm{U}$ is elastic energy density, $\mathrm{e}_{I}=\mathrm{e}_{i j}$ (i or $\mathrm{j}=\mathrm{x}, \mathrm{y}, \mathrm{z}, \mathrm{I}=1 \ldots 6)$ is a component of a strain tensor. Equations 1 and 2 lead to six second and ten third order elastic constants (SOEC and TOEC) for the hexagonal structure materials [27, 30]:

$$
\left.\begin{array}{rl}
C_{11}=24.1 p^{4} C^{\prime} & C_{12}=5.918 p^{4} C^{\prime} \\
C_{13}=1.925 p^{6} C^{\prime} & C_{33}=3.464 p^{8} C^{\prime} \\
C_{44}=2.309 p^{4} C^{\prime} & C_{66}=9.851 p^{4} C^{\prime}
\end{array}\right\}
$$

where $\mathrm{p}=\mathrm{c} / \mathrm{a}$ : axial ratio; $\mathrm{C}^{\prime}=\chi \mathrm{a} / \mathrm{p}^{5}$; $\mathrm{B}=\psi \mathrm{a}^{3} / \mathrm{p}^{3} ; \chi=(1 / 8)\left[\left\{\mathrm{nb}_{0}(\mathrm{n}-\mathrm{m})\right\} /\left\{\mathrm{a}^{\mathrm{n}+4}\right\}\right] \psi$ $=-\chi /\left\{6 \mathrm{a}^{2}(\mathrm{~m}+\mathrm{n}+6)\right\} ; \mathrm{m}, \mathrm{n}=$ integer quantity; $\mathrm{b}_{0}=$ Lennard Jones parameter.

\subsection{Ultrasonic attenuation and allied parameters}

The Akhieser effect is an energy dissipation effect taking place under a uniform time dependent stress. The propagation of an ultrasonic wave produces a stress in a crystalline material, which causes strain. An incremental change in temperature is caused by alternating strain. This increment in temperature disturbs the equilibrium of phonon distribution, which is equalized to the equilibrium of phonon distribution.

The predominant causes for the ultrasonic attenuation in a solid at room temperature are phonon-phonon interaction (Akhieser loss) and thermoelastic relaxation mechanisms. The ultrasonic attenuation coefficient $(\mathscr{A})_{A k h}$ due to phonon-phonon interaction and thermoelastic loss $(\mathscr{A})_{T h}$ mechanisms is given by the following expression [30, 31]:

$$
\begin{aligned}
\left(\mathscr{A} / f^{2}\right)_{A k h}= & 4 \pi^{2}\left(3 E_{0}<\left(\gamma_{i}^{j}\right)^{2}>\right. \\
& \left.-<\gamma_{i}^{j}>^{2} C_{V} T\right) \tau / 2 \rho V^{3}
\end{aligned}
$$




$$
\left(\mathscr{A} / f^{2}\right)_{T h}=4 \pi^{2}<\gamma_{i}^{j}>^{2} k T / 2 \rho V_{L}{ }^{5}
$$

where, $\mathrm{f}$ - frequency of the ultrasonic wave, $\mathrm{V}$ ultrasonic velocity for longitudinal and shear wave, $\mathrm{V}_{L}$ - longitudinal ultrasonic velocity, $\mathrm{E}_{0}$ - thermal energy density, $\mathrm{k}$ and $\mathrm{C}_{V}$ are the thermal conductivity and specific heat per unit volume of the material, respectively, $\gamma_{i}{ }^{j}$ is Grüneisen number $(i, j$ are the mode and direction of propagation), $\tau$ is thermal relaxation time and $\rho$ is the density of material.

The Grüneisen number for a hexagonally structured crystal along $<001\rangle$ orientation or $\Theta=0^{\circ}$ is a direct consequence of second and third order elastic constants. $D=3\left(3 E_{0}<\left(\gamma_{i}^{j}\right)^{2}>-<\gamma_{i}^{j}>^{2} C_{V} T\right) / E_{0}$ is known as acoustic coupling constant, which is the measure of acoustic energy converted to thermal energy. When the ultrasonic wave propagates through a crystalline material, the equilibrium of phonon distribution is disturbed. The time for re-establishment of equilibrium of the thermal phonon distribution is called thermal relaxation time $(\tau)$ and is given by following expression:

$$
\tau=\tau_{S}=\tau_{L} / 2=3 k / C_{V} V_{D}^{2}
$$

where $\tau_{L}$ and $\tau_{S}$ are the thermal relaxation time for longitudinal and shear wave, respectively. The Debye average velocity $\left(\mathrm{V}_{D}\right)$ is well related to longitudinal $\left(\mathrm{V}_{L}\right)$ and shear wave $\left(\mathrm{V}_{S 1}, \mathrm{~V}_{S 2}\right)$ velocities. The expressions for ultrasonic velocities were found in our previous papers [30, 31].

\section{Results and discussion}

\subsection{Higher order elastic constants}

The unit cell parameters ' $a$ ' (basal plane parameter) and 'p' (axial ratio) for $\mathrm{Li}_{3} \mathrm{~N}$, are $3.641 \AA$ and 1.06 [32] respectively. The value of $m$ and $n$ for $\mathrm{Li}_{3} \mathrm{~N}$ are 6 and 7 . The value of $\mathrm{b}_{0}$ for $\mathrm{Li}_{3} \mathrm{~N}$ is $4.5 \times 10^{-64} \mathrm{erg} \cdot \mathrm{cm}^{7}$. The second order elastic constants (SOEC) and third order elastic constants (TOEC) have been calculated for $\mathrm{Li}_{3} \mathrm{~N}$ using equation 3 and are presented in Table 1. The bulk modulus (B) for $\mathrm{Li}_{3} \mathrm{~N}$ can be calculated with the formula: $B=2\left(C_{11}+C_{12}+2 C_{13}+C_{33} / 2\right) / 9$. The evaluated $\mathrm{B}$ for $\mathrm{Li}_{3} \mathrm{~N}$ is presented in Table 1. The elastic constants of the material are important, since they are related to hardness and, therefore, are of interest in applications where mechanical strength and durability are important. Also, the second order elastic constants are used for the determination of ultrasonic attenuation and related parameters. The calculated SOEC are some different than the theoretically evaluated values by Hossain et al. [32]. Actually, Hossain et al. based on abinitio first principle method for total energy calculation (HF-LCAO, DFT as implemented in CRYSTAL 98 and in CASTEP), which is quite different from the present approach, although the obtained SOECs are of the same order. Relative magnitudes of $\mathrm{C}_{11}, \mathrm{C}_{12}$ and $\mathrm{B}$ obtained by our theoretical approach are in good agreement with other theoretical results, as shown in Table 1. Thus, our theoretical approach for the calculation of second order elastic constants for hexagonally structured compound at room temperature is well justified. However, third order elastic constants have not been compared due to lack of the data in the literature but the negative third order elastic constants have been found in our previous papers for hexagonal structure materials [30, 33-35]. Hence, the theory applied for the evaluation of higher order elastic constants at room temperature is justified.

\subsection{Ultrasonic velocity and allied parameters}

The temperature dependent density and thermal conductivity have been taken from the literature [36]. The value of $\mathrm{C}_{V}$ and $\mathrm{E}_{0}$ have been evaluated using tables of physical constants and Debye temperature. The value of temperature dependent density $(\rho)$, specific heat per unit volume $\left(C_{V}\right)$, thermal energy density $\left(\mathrm{E}_{0}\right)$ thermal conductivity (k) and calculated acoustic coupling constants $\left(\mathrm{D}_{L}\right.$ and $\mathrm{D}_{S}$ ) are presented in Table 2.

The computed orientation dependent ultrasonic wave velocities and Debye average velocities at $300 \mathrm{~K}$ are shown in Fig. 1 to 4 . Fig. 1 to 3 show that the velocities $\mathrm{V}_{S 1}$ have maxima at $40^{\circ}$ with the unique axis of the crystal while $\mathrm{V}_{L}$ and $\mathrm{V}_{S 2}$ increase with the angle from the unique axis. The combined effect of SOEC and density is the 
Table 1. SOEC, TOEC and B in the unit of $10^{10} \mathrm{~N} \cdot \mathrm{m}^{-2}$ of $\mathrm{Li}_{3} \mathrm{~N}$ at room temperature.

\begin{tabular}{|c|c|c|c|c|c|c|c|c|c|c|}
\hline & & $\mathrm{C}_{11}$ & $\mathrm{C}_{12}$ & $\mathrm{C}_{13}$ & $\mathrm{C}_{33}$ & $\mathrm{C}_{44}$ & $\mathrm{C}_{66}$ & $\mathrm{~B}$ & & \\
\hline & $\mathrm{Li}_{3} \mathrm{~N}$ & 16.03 & 3.94 & 2.69 & 10.18 & 3.23 & 6.29 & 6.76 & & \\
\hline & [32] $\mathrm{Li}_{3} \mathrm{~N}$ & 16.57 & 2.27 & 0.83 & 18.00 & 1.81 & & 6.39 & & \\
\hline & $\mathrm{C}_{111}$ & $\mathrm{C}_{112}$ & $\mathrm{C}_{113}$ & $\mathrm{C}_{123}$ & $\mathrm{C}_{133}$ & $\mathrm{C}_{344}$ & $\mathrm{C}_{144}$ & $\mathrm{C}_{155}$ & $\mathrm{C}_{222}$ & $\mathrm{C}_{333}$ \\
\hline $\mathrm{Li}_{3} \mathrm{~N}$ & -261.35 & -41.44 & -6.90 & -8.77 & -34.39 & -32.25 & -10.22 & -6.81 & -206.79 & -101.69 \\
\hline
\end{tabular}

Table 2. Density $\rho$, specific heat per unit volume $\mathrm{C}_{V}$, thermal energy density $\mathrm{E}_{0}$, thermal conductivity $\mathrm{k}$ and acoustic coupling constants $\left(\mathrm{D}_{L} \mathrm{D}_{S}\right)$ of $\mathrm{Li}_{3} \mathrm{~N}$.

\begin{tabular}{ccccccc}
\hline $\begin{array}{c}\text { Temp. } \\
\left({ }^{\circ} \mathrm{C}\right)\end{array}$ & $\begin{array}{c}\rho \\
\left(10^{3} \mathrm{~kg} \cdot \mathrm{m}^{-3}\right)\end{array}$ & $\begin{array}{c}\mathrm{C}_{V} \\
\left(10^{5} \mathrm{~J} \cdot \mathrm{m}^{-3} \cdot \mathrm{K}^{-1}\right)\end{array}$ & $\begin{array}{c}\mathrm{E}_{0} \\
\left(10^{6} \mathrm{~J} \cdot \mathrm{m}^{-3}\right)\end{array}$ & $\begin{array}{c}\mathrm{k} \\
\left(\mathrm{W} \cdot \mathrm{m}^{-1} \cdot \mathrm{K}^{-1}\right)\end{array}$ & $\mathrm{D}_{L}$ & $\mathrm{D}_{S}$ \\
\hline \hline 50 & 1.32 & 0.35 & 0.51 & 32 & 37.23 & 4.12 \\
100 & 1.31 & 2.42 & 7.27 & 19 & 37.34 & 4.13 \\
200 & 1.29 & 6.00 & 52.27 & 12 & 38.44 & 4.13 \\
300 & 1.27 & 7.53 & 120.37 & 8 & 38.88 & 4.13 \\
\hline
\end{tabular}

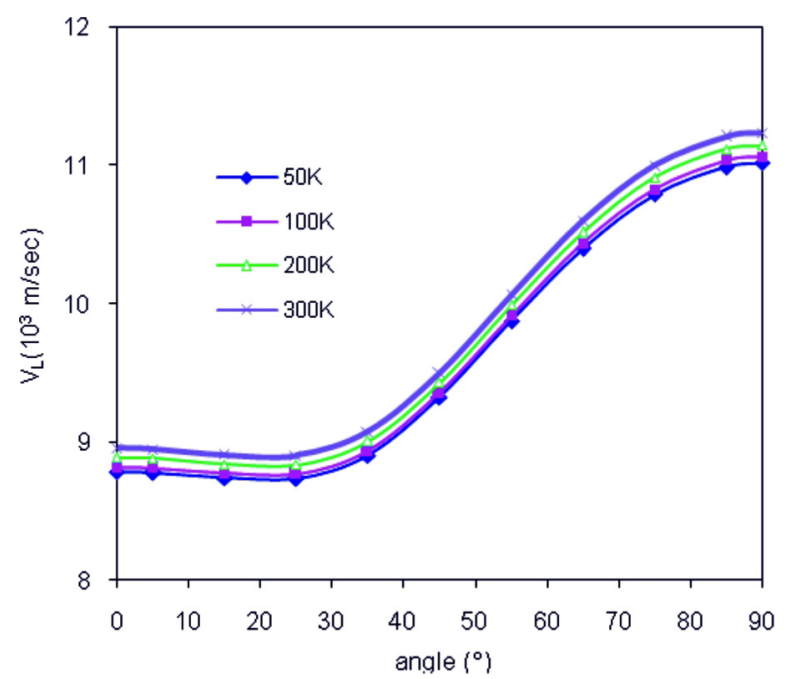

Fig. 1. $\mathrm{V}_{L}$ vs. angle $\left({ }^{\circ}\right)$ with unique axis of crystal.

reason for abnormal behavior of the angle dependent velocities. The nature of the angle dependent velocity curves in the present work is found similar to that for the third group nitrides, heavy rare-earth metals, laves-phase compounds and other hexagonal wurtzite structured materials [31, 33-35]. The chosen compound has the properties similar to their crystal structures. Thus, the angle dependencies of the velocities in $\mathrm{Li}_{3} \mathrm{~N}$ are justified.

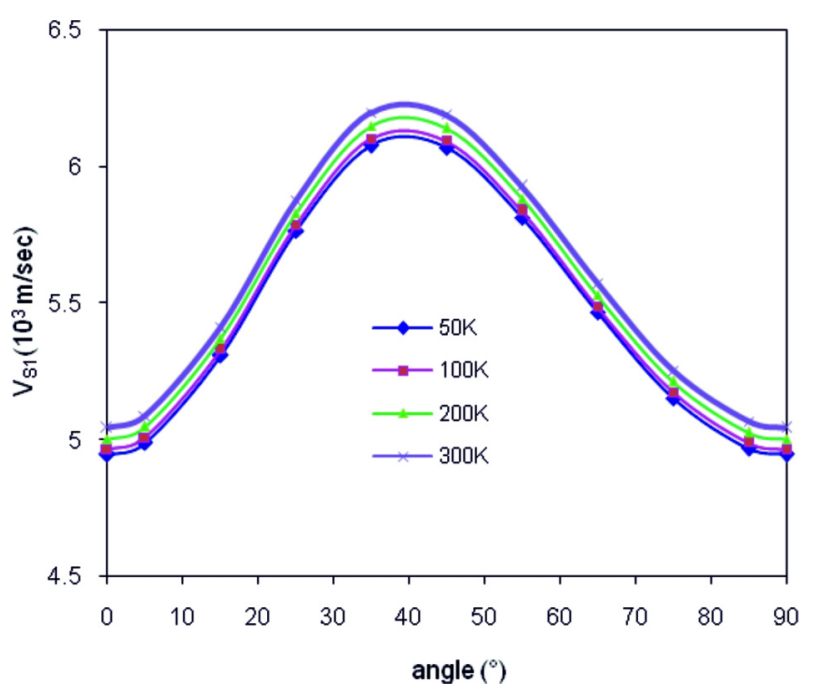

Fig. 2. $\mathrm{V}_{S 1}$ vs. angle $\left({ }^{\circ}\right)$ with unique axis of crystal.

$\mathrm{V}_{D}$ of this material is increasing with the angle and has maxima at $55^{\circ}$ in the range of 50 to $300 \mathrm{~K}$ (Fig. 4). Since $\mathrm{V}_{D}$ is calculated using $\mathrm{V}_{L}, \mathrm{~V}_{S 1}$ and $\mathrm{V}_{S 2}[27,30]$, therefore, the angle variation of $\mathrm{V}_{D}$ is influenced by the constituent ultrasonic velocities. The maximum $\mathrm{V}_{D}$ at $55^{\circ}$ is due to a significant increase in longitudinal and pure shear $\left(\mathrm{V}_{S 2}\right)$ wave velocities and a decrease in quasi-shear $\left(\mathrm{V}_{S 1}\right)$ wave velocity. Thus, it can be concluded that when 


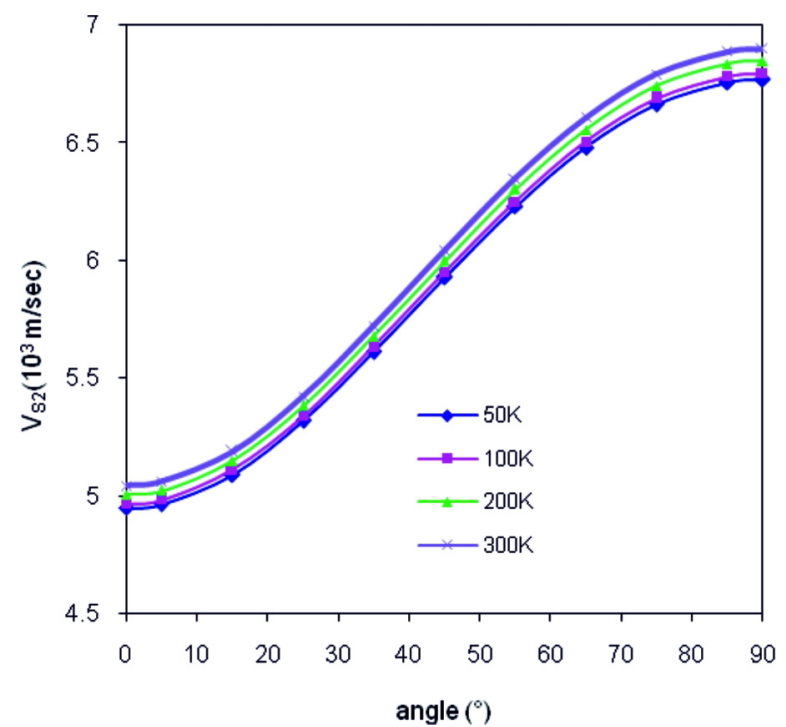

Fig. 3. $V_{S 2}$ vs. angle $\left({ }^{\circ}\right)$ with unique axis of crystal.

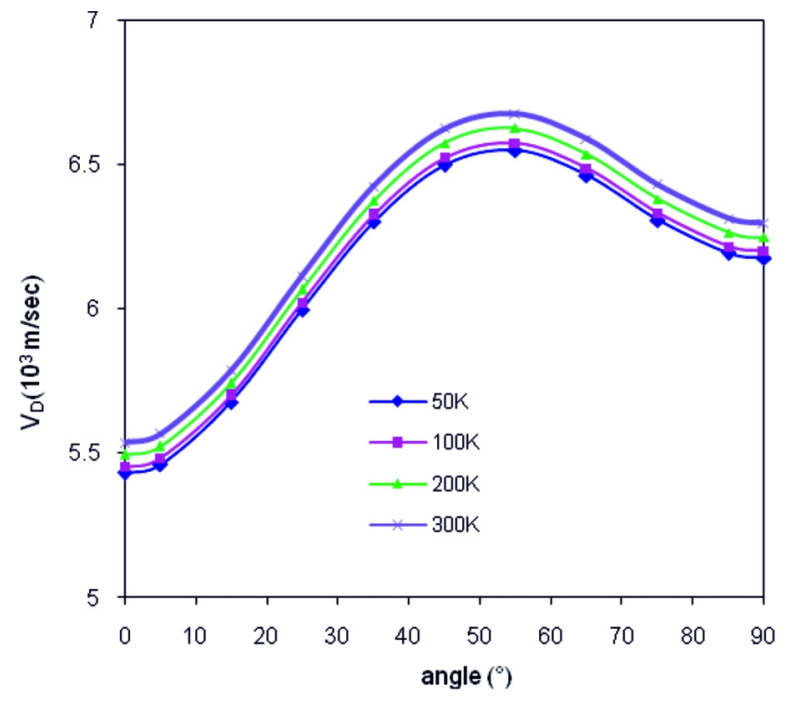

Fig. 4. $\mathrm{V}_{D}$ vs. angle $\left({ }^{\circ}\right)$ with unique axis of crystal.

a sound wave travels at $55^{\circ}$ along the unique axis of these crystals then the average sound wave velocity is maximum.

The calculated thermal relaxation time is visualized in Fig. 5. The angle dependent thermal relaxation time curves follow the reciprocal nature of $\mathrm{V}_{D}$ as $\tau \propto 3 \mathrm{k} / \mathrm{C}_{V} \mathrm{~V}_{D}^{2}$. This implies that ' $\tau$ ' for the chosen compound is mainly affected by the thermal conductivity. The thermal relaxation time for hcp structured material follows the equation: $\tau=\tau_{0} \exp (x / \lambda)$, where $\tau$ and $\lambda$ are constants.

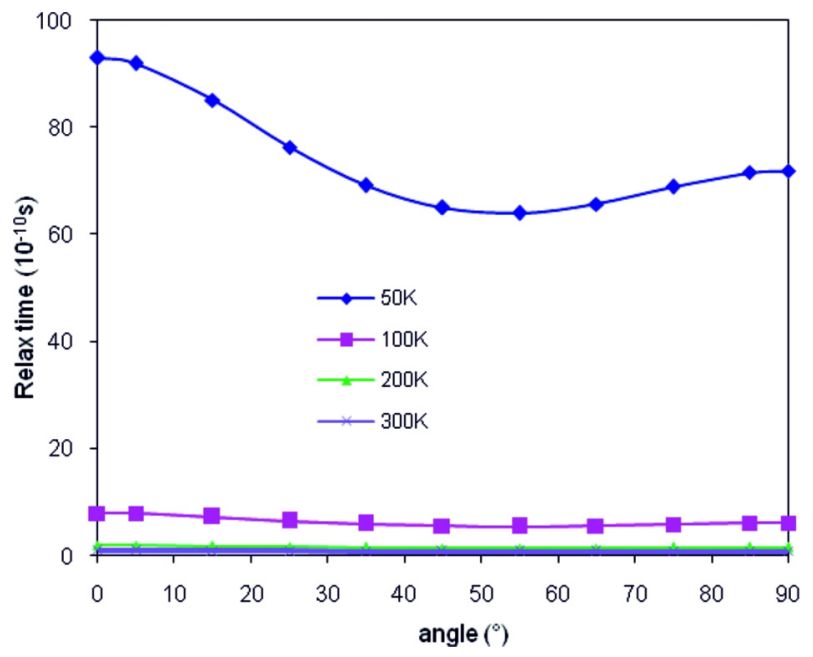

Fig. 5. Relaxation time vs. angle $\left({ }^{\circ}\right)$ with unique axis of crystal.

The order of ' $\tau$ ' for hexagonal structure is of the order of picoseconds [35]. With reference to some previous work [37], the size dependency of $\tau$ for bcc and fcc structured materials follows the equation: $\tau=\tau_{0}[1-\exp (-x / \lambda)]$. Thus, it can be said that the thermal relaxation time is not only a function of size and temperature but also depends on the structure of a material. The order of thermal relaxation time for $\mathrm{Li}_{3} \mathrm{~N}$ has been found in picoseconds, which justifies their hexagonal structure. The re-establishment time for the equilibrium distribution of thermal phonons attains minimum for the wave propagation along $\Theta=55^{\circ}$ due to being the smallest value of $\tau$ along this direction. Thus, the present average sound velocity directly correlates with the Debye temperature, specific heat and thermal energy density of $\mathrm{Li}_{3} \mathrm{~N}$.

\subsection{Ultrasonic attenuation due to phonon- phonon interaction and thermal relaxation phenomena}

In the evaluation of ultrasonic attenuation, it is supposed that a wave is propagating along the unique axis $\left(<001>\right.$ direction) of $\mathrm{Li}_{3} \mathrm{~N}$. The attenuation coefficients over frequency square $\left(\mathscr{A} / \mathrm{f}^{2}\right)_{A k h}$ for the longitudinal $\left(\mathscr{A} / \mathrm{f}^{2}\right)_{L}$ and shear wave $\left(\mathscr{A} / \mathrm{f}^{2}\right)_{S}$ have been calculated using equation 4 under the condition $\omega \tau \ll 1$ at different temperatures. The thermoelastic loss over frequency square 


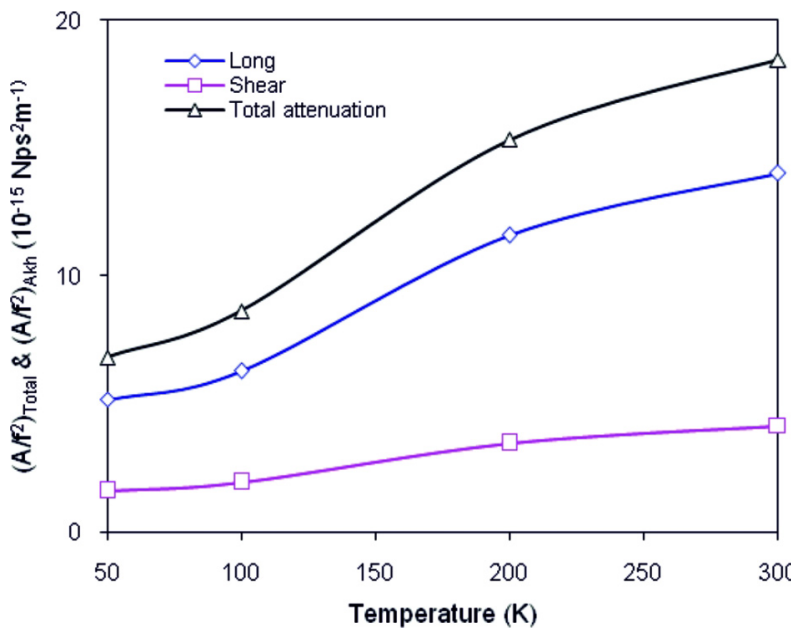

Fig. 6. $\left(\mathscr{A} / \mathrm{f}^{2}\right)_{\text {Total }}$ and $\left(\mathscr{A} / \mathrm{f}^{2}\right)_{A k h}$ vs. temperature of $\mathrm{Li}_{3} \mathrm{~N}$.

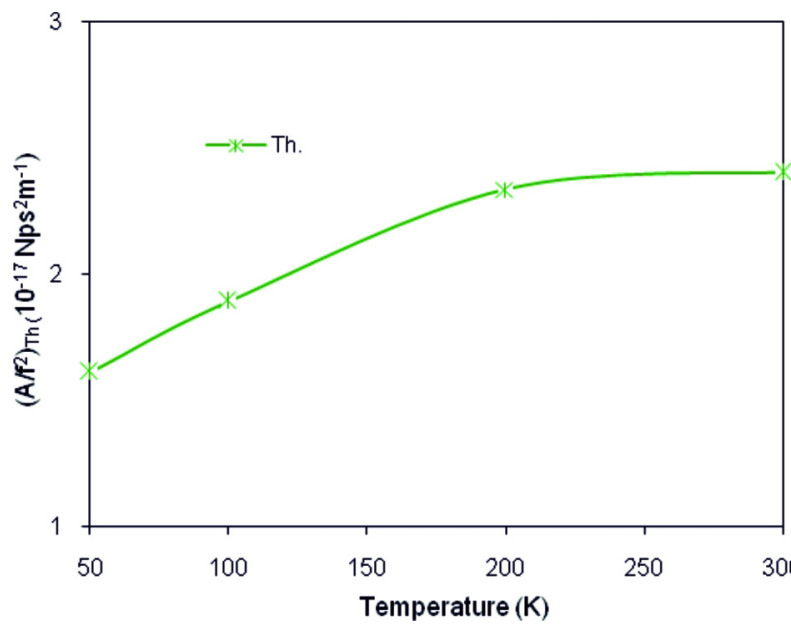

Fig. 7. $\left(\mathscr{A} / \mathrm{f}^{2}\right)_{T h}$ vs. temperature of $\mathrm{Li}_{3} \mathrm{~N}$.

$\left(\mathscr{A} / \mathrm{f}^{2}\right)_{T h}$ has been calculated with the equation 5 . The values of temperature dependent $\left(\mathscr{A} / \mathrm{f}^{2}\right)_{L}$, $\left(\mathscr{A} / \mathrm{f}^{2}\right)_{S},\left(\mathscr{A} / \mathrm{f}^{2}\right)_{T h}$ and total attenuation $\left(\mathscr{A} / \mathrm{f}^{2}\right)_{\text {Total }}$ are presented in Fig. 6 to 7.

In the present investigation, the ultrasonic wave propagates along the unique axis of the crystal, and the Akhieser type of loss of energy for longitudinal and shear wave as well as thermo elastic loss increase with the temperature of the material (Fig. 6 and 7). $\left(\mathscr{A} / \mathrm{f}^{2}\right)_{A k h}$ is proportional to $\mathrm{D}, \mathrm{E}_{0}, \tau$ and $\mathrm{V}^{-3}$ (equations 4 and 6). The $\mathrm{E}_{0}$ is increasing and $\mathrm{V}$ is decreasing with the temperature (Fig. 1 to 3 ). Hence, Akhieser loss in $\mathrm{Li}_{3} \mathrm{~N}$ is predominantly affected by the thermal energy density $\mathrm{E}_{0}$ and the thermal conductivity.

Therefore, the ultrasonic attenuation increases due to the reduction of the thermal conductivity. Thus, ultrasonic attenuation is mainly governed by the phonon-phonon interaction mechanism. A comparison of the ultrasonic attenuations could not be made due to lack of experimental data in the literature.

Fig. 6 to 7 indicate that the thermoelastic loss is very small in comparison to Akhieser loss and ultrasonic attenuation for the longitudinal wave $\left(\mathscr{A} / f^{2}\right)_{L}$ is greater than that of the shear wave $\left.\left(\mathscr{A} / f^{2}\right)_{S}\right)$. This reveals that ultrasonic attenuation due to phonon-phonon interaction along the longitudinal wave is a governing factor for total attenuation: $\left(\left(\mathscr{A} / f^{2}\right)_{\text {Total }}=\right.$ $\left.\left(\mathscr{A} / f^{2}\right)_{T h}+\left(\mathscr{A} / f^{2}\right)_{L}+\left(\mathscr{A} / f^{2}\right)_{S}\right)$. The total attenuation is mainly affected by thermal energy density and thermal conductivity. Thus, it may be predicted that at $50 \mathrm{~K}, \mathrm{Li}_{3} \mathrm{~N}$ behaves as its purest form and is more ductile as evinced by minimum attenuation while at $300 \mathrm{~K}, \mathrm{Li}_{3} \mathrm{~N}$ is least ductile. Therefore, impurity content will be the least in the $\mathrm{Li}_{3} \mathrm{~N}$ at low temperature. The total attenuation of $\mathrm{Li}_{3} \mathrm{~N}$ is much larger than that of the third group nitrides $\left(\mathrm{AlN}: 4.441 \times 10^{-17} \mathrm{~Np} \cdot \mathrm{s}^{2} \cdot \mathrm{m}^{-1}\right.$; GaN: $14.930 \times 10^{-17} \mathrm{~Np} \cdot \mathrm{s}^{2} \cdot \mathrm{m}^{-1}$ and $\mathrm{InN}$ : $20.539 \times 10^{-17} \mathrm{~Np} \cdot \mathrm{s}^{2} \cdot \mathrm{m}^{-1}$ ) due to their large thermal conductivity and acoustic coupling constants $[35,38]$. This implies that the interaction between acoustical phonon and quanta of lattice vibration for $\mathrm{Li}_{3} \mathrm{~N}$ is large in comparison to third group nitrides.

\section{Conclusions}

Our theory of higher order elastic constants is justified for the superionic conductor material. The order of thermal relaxation time for $\mathrm{Li}_{3} \mathrm{~N}$ has been found in picoseconds, which justifies its hexagonal structure. The re-establishment time for the equilibrium distribution of thermal phonons is minimum for the wave propagation along $\Theta=55^{\circ}$ due to the smallest value of relaxation time along this direction. However, the acoustic coupling constants 
of $\mathrm{Li}_{3} \mathrm{~N}$ for longitudinal wave are found four times larger than for the third group nitrides. Hence, the conversion of acoustic energy into thermal energy will be larger for $\mathrm{Li}_{3} \mathrm{~N}$. This shows general suitability of the chosen material. The ultrasonic attenuation, due to phonon-phonon interaction mechanism, is predominant over the total attenuation as a factor governing thermal conductivity. The mechanical properties (yield strength, ductility, elastic properties, etc.) of $\mathrm{Li}_{3} \mathrm{~N}$ at low temperature $(50 \mathrm{~K})$ are better than at high temperature $(300 \mathrm{~K})$, because at low temperature the material has low ultrasonic attenuation.

Thus, the results obtained in the present work can be used for further investigations as well as in general and industrial applications. Our theoretical approach is valid for temperature dependent ultrasonic characterization of $\mathrm{Li}_{3} \mathrm{~N}$. The ultrasonic behavior of $\mathrm{Li}_{3} \mathrm{~N}$ shows important microstructural characteristic features, which are well connected to thermoelectric properties of the material. These results, together with other well-known physical properties, may expand future prospects for the application and study of $\mathrm{Li}_{3} \mathrm{~N}$.

\section{References}

[1] Kharton V.V. (ED.), Solid state electrochemistry: Fundamentals, materials and their applications, WileyVCH Verlag GmbH \& Co. KGaA, Weinheim, 2009.

[2] Thangadurai V., Weppner W., Ionics, 12 (2006), 81.

[3] Roth W.L., FArrington G.C., Science, 196 (1977), 1332.

[4] Raistrick I.D., Ho C., Huggins R.A., J. Electrochem. Soc., 123 (1976), 1469.

[5] Huggins R.A., Electrochim. Acta, 22 (1977), 773.

[6] KNAUth P., Solid State Ionics, 180 (2009), 911.

[7] Alpen U.V., Rabenau A., Talat G.H., Appl. Phys. Lett., 30 (1977), 621.

[8] Boukamp B.A., Huggins R.A., Mater. Res. Bull., 13 (1978), 23

[9] Alpen U.V., J. Solid State Chem., 29 (1979), 379.

[10] Rea J.R., Foster D.L., Mallory P.R., Co I., Mater. Res. Bull., 14 (1979), 841.

[11] Chen P., Xiong Z., Luo J., Lin J., Tan K.L., Nature, 420 (2002), 302.

[12] Rabenau A., Lithium Nitride, an unusual Ionie Conduetor, in: Treusch J. (Ed.), Festkörperprobleme (Advances in Solid State Physics), Vol. 18, Vieweg, Braunschweig, 1978, p. 77.
[13] Ichikawa T., Isobe S., Hanada N., FujiI H., J. Alloy. Compd., 365 (2004), 271.

[14] Hu Y.H., Ruckenstein E., Ind. Eng. Chem. Res., 44 (2005), 1510.

[15] Nakamori Y., Kitahara G., Miwa K., Towata S., Orimo S., Appl. Phys. A-Mater., 80 (2005), 1.

[16] Xie Y., Qian Y., Wang W., Zhang S., Zhang Y., Science, 272 (1996), 1926.

[17] Hunklinger S., J. Physique, 39 (1978), C6 1444 (1$6)$.

[18] TARascon J.M, Armand M., Nature, 414, (2001), 359.

[19] Dell R.M., Solid State Ionics, 134 (2000), 139.

[20] Tillement O., Solid State Ionics, 68 (1994), 9.

[21] Chaudhary K.D., Z. Phys. A-Hadron. Nucl., 155 (1959), 290.

[22] Yadav R.R., Gupta A.K., Singh D., J. Phys. Stud., 9 (2005), 227.

[23] Kor S.K., Tandon U.S., Rai G., Phys. Rev. B, 6 (1972), 2195.

[24] Kor S.K., Singh R.K., Acta Phys. Pol. A, 83 (1993), 751.

[25] YADAV R.R., SINGH D., Intermetallics, 9 (2001), 189.

[26] Singh D., Yadawa P.K., Platin. Met. Rev., 54 (2010), 172.

[27] Yadawa P.K., Singh D., Pandey D.K., YadaV R.R., The Open Acoustic Journal, 2 (2009), 80.

[28] RaVindran P., FAST L., KorzhaVyi P.A., Johansson B., Wills J.M., Eriksson O., J. Appl. Phys., 84 (1998), 4891.

[29] Louail L., Maouche D., Roumili A., Sahraoui A.F., Mater. Lett., 58 (2004), 2975.

[30] YAdAV A.K., YADAV R.R., PANDEY D.K., Singh D., Mater. Lett., 62 (2008), 3258.

[31] Pandey D.K., Yadawa P.K., YadaV R.R., Mater. Lett., 61 (2007), 5194.

[32] Hossain M.A., ISLAm A.K., ISLAm F.N., J. Sci. Res., 1 (2009), 182.

[33] Pandey D.K., Yadawa P.K., YadaV R.R., Mater. Lett., 61 (2007), 4747.

[34] Pandey D.K., Singh D., Yadawa P.K., Platin. Met. Rev. 53 (2009), 91.

[35] Pandey D.K., Singh D., Yadav R.R., Appl. Acoust., 68 (2007), 766.

[36] Guckelsberger K., DE Goer A.M., J. Phys. CSolid State Phys., 13 (1980), L767.

[37] YAdAWA P.K., Ceram.-Silikaty, 55 (2011), 127.

[38] Hellwege K.H., Hellwege A.M. (Eds.), LandoltBörnstein: Numerical Data and Functional Relationships in Science and Technology, Group III, Vol. 11, Springer, Berlin, 1979. 